(C)British Editorial Society of Bone and Joint Surgery doi:10.1302/0301-620X.90B2.20167 \$2.00 J Bone Joint Surg [Br] 2008;90-B:264.

\section{Orthopaedic basic science, foundations of clinical practice, third edition}

Edited by T. A. Einhorn, R. J. O'Keefe, J. A. Buckwater

Pp. 465. Rosemont: American Academy of Orthopaedic Surgeons, 2007. ISBN: 13-9780892033577. \$197.95

The third edition of Orthopaedic Basic Science, a multi-author text, is a valuable resource for orthopaedic surgeons, both in terms of continuous professional development, but particularly for trainees and those approaching the examination. The size of the book, less than 500 pages, and the use of acknowledged world experts, makes this probably the definitive study document. The book assumes a certain prior knowledge; a good example is the Biomechanics chapter which assumes that the readers can recall their trigonometry. But for the most part, the editors rely upon descriptions supported by simple diagrams and tables of important facts that allow the reader to compare and contrast common materials. I particularly admired Chapter 5, Evidence Based Orthopaedics, by Bhandari, which describes how to set up a research project. The section on error analysis is elegantly simple.

There are certain differences in approach for an American readership which make the book marginally limiting for the international market, but by and large this is avoided; a good example is Chapter 6 in which the facts behind the risk in pulmonary embolism are laid out without indulging in the overly defensive treatment. If every orthopaedic surgeon was familiar with the context of this text, their fundamental understanding of the science behind their subject would be enhanced.

Some of the later chapters are, in my view, somewhat superficial, particularly in terms of some of the latest thinking behind bone healing and repair; but there is a useful summary of this important area. Understanding at this level would certaily get an individual through the examination, but there is perhaps not sufficient detail to understand some of the current arguments that are raging around the use of the various therapies. The chapter on the Molecular Basis of Cancer is valuable with some memorable diagrams. As a CPD text this is a well worthwhile read and for surgeons in training it should allow them to enter the process of assessment with confidence.

D. I. Rowley

\section{Practical orthopaedic sports medicine and arthroscopy Edited by D. H. Johnson, R. A. Pedowitz}

Pp. 1066. Philadelphia: Lippincott Williams \& Wilkins, 2006. ISBN: 0-78175812-2. \$259.00.

I found this a very difficult book to review. "Orthopaedic Sports Medicine" is not a concept that is familiar to UK Orthopaedics. We do have a faculty of Sports and Exercise Medicine in the
United Kingdom but this includes only one working orthopaedic surgeon. Most orthopaedic surgeons treating sportsmen and women have a subspecialist interest and are foot and ankle surgeons, shoulder surgeons, knee surgeons etc., so it is difficult to know who this text is aimed at.

For a general overview of the subject and what might be achieved by arthroscopic surgery, it is fairly comprehensive. It is well illustrated and generally readable, although somewhat slanted towards an American point of view. The introduction states, "to provide a global perspective, we have tapped the knowledge of the top innovators in orthopaedic sports medicine from around the world", but a quick perusal of the list of contributors reveals only four of 130 authors come from outside the North American continent and only a single contributor from the United Kingdom. Is there really such limited expertise in the rest of the world?

There are one or two oddities. For example, chapters on high tibial osteotomy and unicompartmental knee replacement have found their way into the text. I have never seen a competitive sportsman or woman return to the same level of sport after either of these procedures and there remains considerable debate about the wisdom of deliberately stressing a joint replacement. In fact, neither chapter mentions return to sport so they are presumably seen as salvage procedures for retired athletes.

In summary, I think this book may be a useful read for orthopaedic trainees and would be a useful addition to any orthopaedic library as a reference text, but for the average practising orthopaedic surgeon in the United Kingdom, its usefulness is limited.

S. Bollen

\section{Surgeons, manufacturers and patients: a transatlantic history of total hip replacement}

Edited by J. Anderson, F. Neary, J. V. Pickstone

Pp. 222. Basingstoke: Palgrave Macmillan, 2007. ISBN: 13-9780230553149. $£ 45.00$.

This little book traces the modern history of hip replacement with scrupulous journalistic research into the major participants and manufacturing companies. It is essentially light weight but with insights into the clashes of personalities and biased prototype opinions. The reader is charmed by the serendipity of the leaders of the field and feels gratitude at the influence of good fortune in the development of one of the most successful operations of the last century. To quote the book's final paragraph, "For all the innovation as the industry expanded and globalised, many of the resultant THR prostheses (and operations) were worse documented, more expensive and less effective than those produced by the early programmes."

M. Laurence 